\title{
DINHEIRO AINDA GERA VOTO? UMA ANÁLISE DESCRITIVA DOS GASTOS ELEITORAIS DOS CANDIDATOS A VEREADOR EM BELO HORIZONTE.
}

\author{
Henrique Oliveira Rachid Cançado ${ }^{1}$
}

\begin{abstract}
Resumo
Aplicando a teoria da escolha racional no fenômeno eleitoral, surge um campo de pesquisa da Ciência Política que se dedica a entender todas as variáveis que influenciam no voto. Uma hipótese é o fato de que o dinheiro pode ser o maior determinante no resultado eleitoral. Essa crença não é infundada, existem evidências que levam a esse raciocínio. Gary Jacobson $(1978 ; 1980 ; 1981 ; 1987 ; 1990)$ verificou o impacto financeiro nas presidenciais norte-americanas. Em estudo pioneiro, Samuels (2001) constata que a relação entre dinheiro e voto também ocorre nas eleições brasileiras. "Mensurar o efeito do gasto de campanha sobre os resultados eleitorais se tornou um tema canônico na Ciência Política"(FIGUEIREDO FILHO, PARANHOS, CARVALHO DA ROCHA; SILVA JÚNIOR e LAVAREDA, 2013, p. 31). Pois bem, em uma campanha que foi significativamente mais barata devido às novas regras como o limite de gastos, fim das doações empresariais e tempo menor de campanha, é necessário que se verifique: será que dinheiro ainda gera voto? O estudo de caso se refere a todas as candidaturas para o cargo de vereador em Belo Horizonte em 2016 que apresentaram suas despesas para a Justiça Eleitoral. Foram feitas então análises de correlação (coeficiente de Pearson) e p valor para verificar a interação entre dinheiro e voto. Em seguida uma regressão loess (com suavização dos dados) ilustra o comportamento dessa interação. Ainda foi testado modelo de regressão com as variáveis sexo, sigla, despesa e incumbency, para explicar o voto. O modelo foi sobreposto com os dados reais.
\end{abstract}

Palavras-Chave: comportamento político; money matters; dinheiro; financiamento eleitoral;

\section{INTRODUÇÃO}

De acordo com Anthony Downs (1957), o comportamento dos indivíduos é explicado como uma análise de perdas e ganhos, categorizados por ordem de prioridade conforme suas crenças, valores e objetivos antes da escolha. Aplicando a teoria da escolha racional no fenômeno eleitoral, surge um vasto campo de pesquisa da Ciência Política que se dedica a entender todas as variáveis que influenciam no voto. Quais são os determinantes que levam a vitória eleitoral?

Graduado em Ciências Sociais (Bacharelado e Licenciatura) pela Universidade Federal de Minas Gerais. henriquerachidcancado@gmail.com 
Muitos são os trabalhos que buscam os fatores que determinam a escolha eleitoral. (PALDA e PALDA, 1973; JACOBSON, 1978; 1980; 1981; 1987; 1990; GERBER 1998; SAMUELS 2001; ANSOLAHERE, FIGUEIREDO e SNYDER, 2003; GREEN e KRASNO, 2004; FIGUEIREDO FILHO, 2005; PEREIRA e RENNÓ, 2001; 2007; MARCELINO, 2010; PEIXOTO, 2010, BOLOGNESI e CERVI, 2011; BACKES e SANTOS, 2012; MANCUSO e SPECK, 2013; CASTRO e NUNES, 2014 ; ARRAES, AMORIM NETO e SIMONASSI, 2017). O objetivo de todos esses autores é calcular o peso relativo das questões que interferem no total de votos.

Quais são as variáveis que decidem o jogo? O que leva uma pessoa a votar em um candidato e não no outro? Entender o que determina uma eleição é uma pergunta inerente ao processo político, "os determinantes dos resultados eleitorais são também decisivos para a organização dos partidos e conteúdo das políticas governamentais" (ARRAES, AMORIM NETO, SIMONASSI, 2017, pp. 1059). Em outras palavras, as influências decisivas na hora da campanha podem vir a ser fator de pressão para o mandato eleito, ou seja, grupos de interesse, poder financeiro, militância e até orientações partidárias.

Sabe-se que os causadores do voto podem ser diversos; variáveis como a reeleição (JACOBSON, 1978), o nível de riqueza de um candidato (GERBER, 1998), as características geográficas (SAMUELS, 2001), os grupos de interesse organizados (ANSOLAHERE, FIGUEIREDO e SNYDER (2003), o sistema proporcional de lista aberta (NICOLAU, 2006), o horário gratuito de propaganda eleitoral (CERVI, 2011), o sexo e o capital político dos candidatos (MANCUSO e SPECK, 2013) influenciam no resultado final. Ainda se consideram os aspectos culturais, as agremiações partidárias e as regras de financiamento, além do recurso investido pelos candidatos.

Uma hipótese, constantemente estudada pela literatura, é o fato de que o dinheiro pode ser o maior determinante no resultado eleitoral. Essa crença não é infundada, existem evidências que levam a esse raciocínio. Gary Jacobson $(1978 ; 1980 ; 1981 ; 1987 ; 1990)$ estudou o impacto financeiro nas presidenciais norte-americanas e percebeu que existe uma relação positiva entre gastos e total de votos. Segundo suas conclusões, os gastos de candidatos desafiantes têm alto impacto no resultado eleitoral, entretanto para os candidatos situacionais esse impacto é baixo.

Outro autor que atesta essa relação é Gerber (1998). Ele desenvolve um modelo com algumas variáveis socioeconômicas, a fim de verificar se os gastos de campanha na eleição para o 
senado estadunidense estão associados com a probabilidade de vitória de um candidato. Observadas algumas condições como patrimônio do concorrente, experiência política, e gastos partidários nas últimas eleições, ele destaca que os investimentos financeiros de candidatos da situação e dos desafiantes são substancialmente significativos para o resultado eleitoral de ambos.

Em estudo pioneiro, Samuels (2001) constata que a relação entre dinheiro e voto também ocorre nas eleições brasileiras. Ele testou e analisou as campanhas para o cargo de deputado federal em 1994 e uma de suas conclusões é a confirmação estatística de que gastos eleitorais influenciam no resultado do pleito, ou seja, "money matters" também no território tupiniquim. E aponta soluções como o limite de gastos que fariam o poder financeiro ter um peso menor.

Existem outros trabalhos que também comprovam essa relação no Brasil: Backes e Santos (2012) encontraram que, entre as despesas dos candidatos a deputado federal entre 2002 e 2010, os eleitos usaram 12 vezes mais recursos, em média. No trabalho de Sacchet e Speck (2012), a correlação verificada é constantemente alta e significativa. Em outra pesquisa, Speck (2015) mostra como as campanhas brasileiras têm ficado mais caras desde 2002. Rebello, Giora e Scarpini (2016) afirmam, que a literatura é unânime em reconhecer que no caso brasileiro, não há dúvidas de que dinheiro importa. Arraes, Amorim Neto e Simonassi (2017), em trabalho recente, concluem que as possibilidades de vitória de um candidato estão atreladas ao poder econômico da campanha.

Mas essa relação é direta? Se essa premissa é verdadeira quando se fala sobre eleição, então um dos desafios que se coloca é determinar com precisão qual é o efeito do investimento sobre o total de votos. É um anseio e uma cobrança do eleitor, das instituições partidárias e também de diversos autores, analisar os custos de campanha com as suas consequências e desdobramentos para o sistema político.

Em análise feita por Mancuso (2014) sobre os trabalhos da ciência política brasileira acerca de financiamento de campanha e sua relação direta com o voto, o autor mostra que a literatura nacional se organiza em torno de três grandes questões: a) o investimento eleitoral e o resultado; b) o investimento eleitoral e os benefícios para o fornecedor/doador?; e c) o que determina o investimento.

No presente artigo, que se enquadra como mais uma ferramenta desse universo de pesquisas, o objetivo é verificar qual foi o efeito real que o dinheiro aplicado pelos candidatos teve no total de votos, dito de outra, medir o verdadeiro impacto dos investimentos individuais no resultado das eleições para vereador em Belo Horizonte, no ano de 2016. Em um sistema político como o brasileiro, no qual o dinheiro sempre esteve presente, ainda não havia ocorrido alterações tão 
significativas como a imposição do limite de gastos e o fim do financiamento empresarial de campanha. Sendo assim, a pergunta de pesquisa que surge é: será que dinheiro ainda gera voto?

Deve-se evocar que, nem todo investimento feito em uma campanha se transforma em voto. Se a estratégia fosse apenas ter recursos, os eleitos seriam sempre os que mais investiram, o que não é verdade. Cabe citar também os candidatos que têm poucos recursos e se elegem. Existem, ainda, os candidatos com muitos recursos que não se elegem. Em ambas situações, a variável financeira não é definitiva para o resultado. É necessário portanto, determinar o impacto dos gastos no total de votos.

Quando se estuda o resultado eleitoral, a discussão não pode ficar restrita apenas a gastar ou não gastar. Foram construídos também modelos estatísticos de regressão com outras variáveis que explicam o resultado das urnas. Compreender quais são as causas do voto pode ser um aspecto decisivo para a construção de melhores estratégias de campanha. A partir do momento que são verificados os pormenores do voto, clarificam-se os fatores determinantes para a escolha dos eleitores. E por consequência, entende-se que a questão financeira é mais uma variável explicativa.

Os dados utilizados são públicos e referentes ao total de despesas declaradas pelas candidaturas. Além disso, em vários países do mundo, a declaração de gastos pelos candidatos não é uma exigência, sendo publicados apenas os gastos das agremiações partidárias. Progressivamente, esses dados no Brasil, tem se tornado mais abertos e acessíveis, isso tem acontecido por causa de dois motivos: a) as reformas no sistema político, que forçam cada vez mais a fiscalização e declaração dos gastos individualizados, com risco de impugnação da chapa que não fizer esse controle; e b) uma informatização dos sistemas da Justiça Eleitoral, que tem dado mais transparência sobre o processo eleitoral, condições essas que fazem com que os dados trabalhados para as eleições de 2016, sejam inéditos.

Portanto, foram apreciados os gastos dos 1225 candidatos a vereador por Belo Horizonte, em 2016. Segundo dados da Justiça Eleitoral, na capital mineira 1.927.460 eleitores estiveram aptos a votar, $45,77 \%$ de homens e 54,17\% mulheres. A cidade elegeu 41 vereadores, 37 homens e 4 mulheres. Consideradas aqui as campanhas que declararam os gastos até a prestação final de contas e que estão no repositório oficial de estatísticas do TSE.

A escolha deste estudo de caso se explica devido a quatro fatores: a) as campanhas para o Legislativo dependem mais de recursos próprios do que as do Executivo (SPECK, 2015); b) minimizar o efeito de forças nacionais; c) escolheu-se o ano de 2016, para que se pudesse analisar as consequências da reforma política de 2015, que teve como objetivo baratear as campanhas 
brasileiras; d) a cidade escolhida foi Belo Horizonte, devido a proximidade espacial e a praticidade de coleta de dados secundários, mas esse estudo poderia ser replicado em quaisquer outros municípios brasileiros, desde que mantidas as formatações no banco de dados.

Várias mudanças surgiram com o fim do financiamento empresarial de campanha que foi definido pelo julgamento da ADI, n ${ }^{\circ}$ 4650, no plenário do STF. A ação foi sentenciada pelo então ministro relator, Luiz Fux:

(...)julgou procedente em parte o pedido formulado na Ação Direta de Inconstitucionalidade (ADI) 4650 para declarar a inconstitucionalidade dos dispositivos legais que autorizavam as contribuições de pessoas jurídicas às campanhas eleitorais, vencidos, em menor extensão, os ministros Teori Zavascki, Celso de Mello e Gilmar Mendes, que davam interpretação conforme, nos termos do voto ora reajustado do ministro Teori Zavascki”. (STF, 2015, ADI, N 4650).

Junto com isso, a Reforma Política de 2015 trouxe novas regras que impactaram sobre o custo das campanhas. As alterações criaram o limite total de gastos, as campanhas também foram mais curtas: se em 2012 o período eleitoral total foi de 90 dias de campanha, em 2016, foram 45 dias.

De maneira geral, pode se dizer que essas mudanças baratearam significativamente a eleição, como será mostrado a seguir. Na capital mineira, os gastos não poderiam ultrapassar mais de $\mathrm{R} \$ 607.600,00$. Conforme a nova regra, para Belo Horizonte, os valores foram definidos com base no cálculo de $70 \%$ do maior valor declarado da última eleição e corrigidos com a inflação. Em 2012, a campanha mais cara foi a de Cristiano da Mata (PT), ele gastou R\$ 648.925,78. Já, em 2016, a campanha que mais gastou foi a de Wellington Magalhães (PTN), que usou R\$448.127,00 e obteve 13.191 votos que o fizeram ser eleito para seu quarto mandato, com um gasto médio de R\$ 33,00 por cada voto. De forma comparativa, a segunda campanha que mais gastou foi a da também situacional Elaine Matozinhos (PTB), ela não conseguiu se eleger, mas declarou ter investido R\$ 374.468,66. Fátima Felix (PSB) foi a candidata com a menor soma de despesa registrada, ela disse ter usado apenas $\mathrm{R} \$ 64,00$ para conseguir 540 votos, custo bem baixo, pouco mais de $\mathrm{R} \$ 0,12$.

Dinheiro ainda teve sua importância: se consideradas as despesas declaradas, o candidato eleito que teve o voto mais caro, foi Léo Burguês com um custo médio impressionante de $\mathrm{R} \$ 90,58$ para cada um dos seus 3519 votos. Na capital mineira, em média, os candidatos a vereador gastaram R \$ 13.660,56, em 2016. Contudo, quando olhamos para as 41 campanhas eleitas, essa média sobe para $\mathrm{R} \$ 118.020,00$, o que nos induz a pensar que, mesmo em uma campanha mais barata, a relação investimento financeiro/desempenho eleitoral existiu.

Mas será que o investimento continua sendo uma variável decisiva no jogo? Osvaldo Lopes (PHS) declarou ter gasto apenas R\$1.500,00 para se eleger com 3.018 votos, um custo médio de 
menos de 50 centavos por voto! Áurea Carolina (PSOL), a candidata eleita com o maior número de votos, declarou ter gasto $\mathrm{R} \$ 58.935,82$ e conseguiu 17.420 votos, média de $\mathrm{R} \$ 3,4$ reais por voto recebido. É curioso ainda, que foram observadas 25 candidaturas registradas e consideradas aptas a concorrer não tiveram nenhum voto, porém em todas houve declaração de gastos.

O banco de dados final totaliza 1.063 .779 votos, os eleitos representam $27 \%$ dos votos do eleitorado. Os 1225 casos observados são distribuídos em 376 mulheres (31\%) e 849 (69\%) homens. Foram 4 candidatas eleitas, os homens foram 37. PHS e PTN foram os partidos que mais elegeram vereadores, cada um com 4 representantes. A Câmara Municipal belo-horizontina eleita é extremamente fragmentada, 22 legendas tem ao menos uma cadeira de representante. O PT foi o partido que mais perdeu vereadores, caiu de 6 cadeiras para 2. Vale citar as duas cadeiras do PSOL, e a cadeira do NOVO, partidos que nunca tiveram um mandato representativo na Câmara de Belo Horizonte.

\section{FIGURA 1. REPRESENTAÇÃO, NÚMERO DE CADEIRAS POR PARTIDO.}

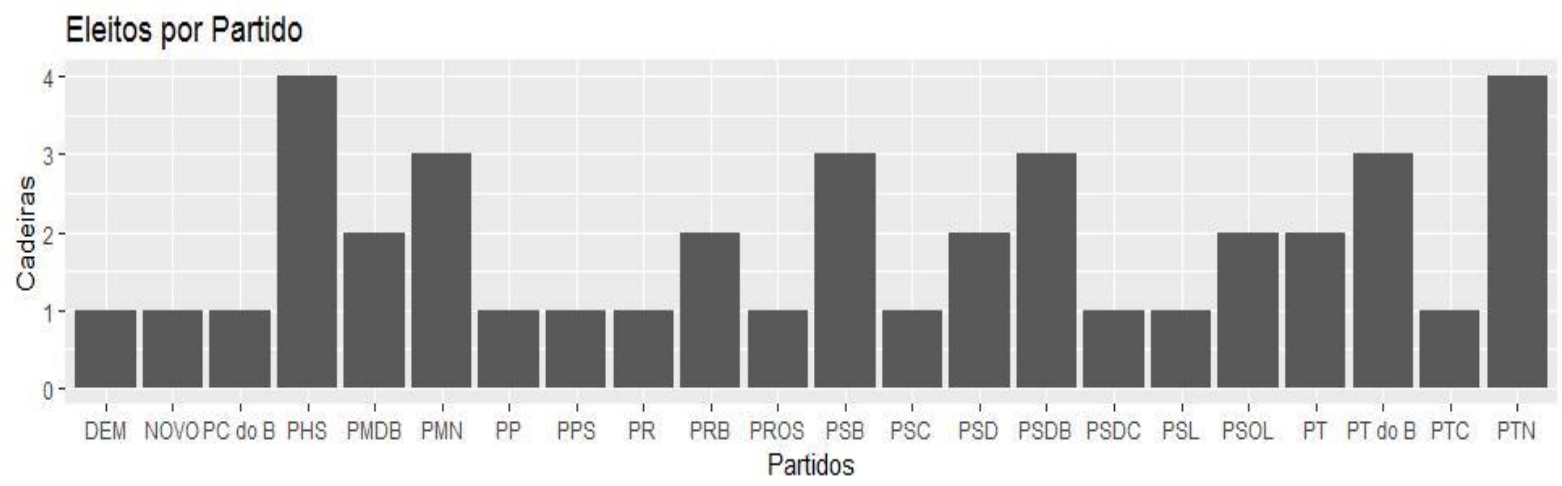

Fonte: O autor, a partir dados do TSE (2018).

Eram 37, os candidatos que concorriam à reeleição, dos quais 18 conseguiram a vitória. Isso pode indicar que a variável "reeleição" influenciou no resultado eleitoral e foi uma variável explicativa no desempenho eleitoral. Ainda assim, o número de novatos, 23 , traduz uma alteração de $56 \%$ das cadeiras de vereadores, o que é um número bem alto para as taxas de renovação se analisarmos as taxas nacionais, de outras casas municipais e também do Congresso Nacional.

O gasto total das campanhas presentes no banco corresponde a um custo de $\mathrm{R} \$$ 16.734.181,00. Se consideradas só as campanhas eleitas, o custo é de R \$ 4.838.818,00, o que representa mais de $25 \%$ de todos os investimentos. O custo médio do voto na campanha analisada foi de $\mathrm{R} \$ 15,70$, os eleitos tiveram um voto a preço médio de $\mathrm{R} \$ 16,80$. 
De fato, os eleitos gastaram realmente mais. Excetuando-se por algumas campanhas mais baratas como a já mencionada do candidato Osvaldo Lopes (PHS), que declarou ter investido um valor de $\mathrm{R} \$ 1.500,00$. Mas em maioria, percebeu-se que o dinheiro ainda esteve bem presente nas campanhas.

\section{FIGURA 2. GASTO DOS CANDIDATOS POR RESULTADO.}

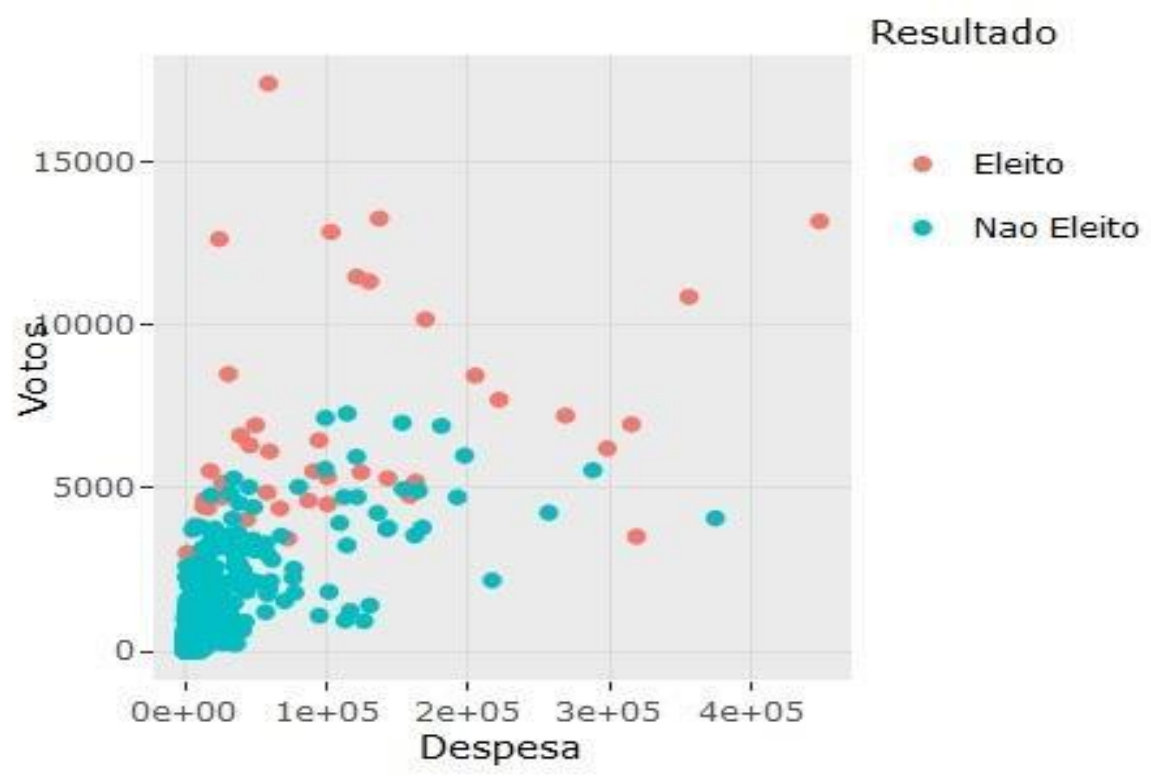

Fonte: O autor, a partir dados do TSE (2018).

\section{DA CORRELAÇÃO, P VALOR E REGRESSÃO LOCAL.}

Mas será que essa relação é direta? As despesas se transformam em votos? Para responder a essa hipótese foi gerado o coeficiente estatístico que explica a relação entre as duas variáveis, o coeficiente de Pearson e o p-valor.

Conforme a tabela abaixo mostra, o $\boldsymbol{\rho}$ encontrado para essa relação no universo geral das campanhas estudadas foi de 0,69 , ou seja a correlação é de moderada a forte. O p-valor de 0 comprova que a hipótese a ser aceita é a alternativa, isto é o valor é significativamente diferente de 0, existe correlação entre dinheiro e voto.

\section{FIGURA 3. DA CORRELAÇÃO, P VALOR E REGRESSÃO LOCAL.}




\begin{tabular}{lrrr} 
Estatistica & $\begin{array}{r}\text { Coeficiente de } \\
\text { Pearson }\end{array}$ & $\begin{array}{r}\text { P- } \\
\text { valor }\end{array}$ \\
\hline Geral & 33.74 & 0.69 & 0 \\
\hline Eleitos & 1.89 & 0.29 & 0.07
\end{tabular}

Fonte: O autor, a partir dados do TSE (2018).

A regressão local gerada que usa a variável despesa para prever o comportamento dos votos, nos 1225 casos permite traçar a reta a seguir:

FIGURA 4. REGRESSÃO LOCAL, A DESPESA PREVENDO O VOTO - CASOS GERAIS.

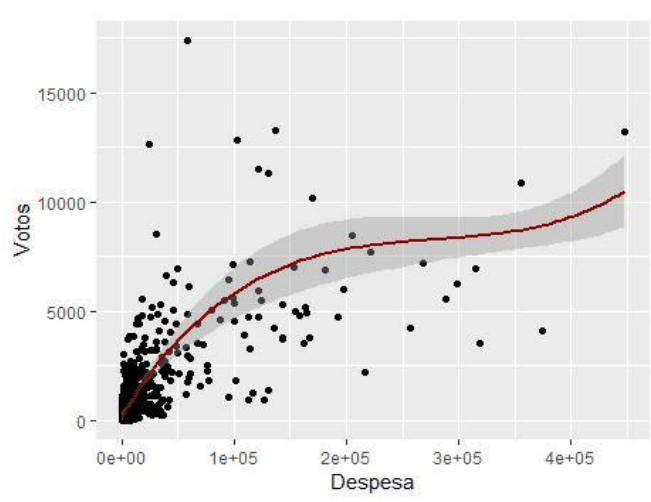

Fonte: O autor, a partir dados do TSE (2018).

A regressão local gerada que usa a variável despesa para prever o comportamento dos votos, nos 41 casos eleitos permite traçar a reta a seguir:

\section{FIGURA 5. REGRESSÃO LOCAL, A DESPESA PREVENDO O VOTO - CASOS}

\section{ELEITOS.}

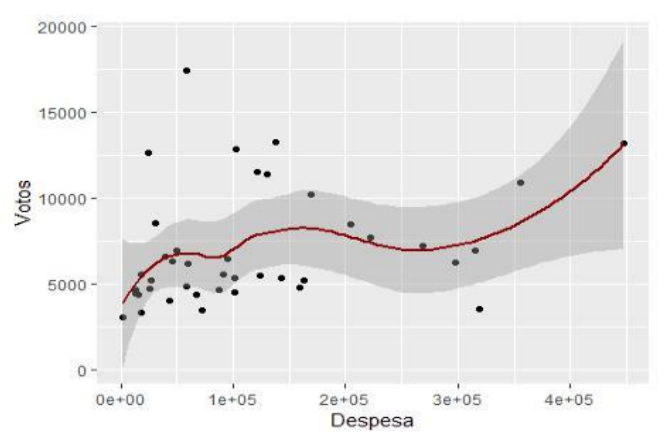

Fonte: O autor, a partir dados do TSE (2018). 
A comprovação que se tem é que de fato a variável despesa esteve influenciando o total de votos. No caso estudado percebeu-se que os dados comprovam que a hipótese de que a quantidade de dinheiro investida está totalmente relacionada com o potencial de eleição de um candidato.

Além disso, a regressão mostrada acima, ainda define uma predição do comportamento do total de votos controlada apenas pela variável dinheiro. A área em cinza foi criada com os pontos vizinhos. E a reta vermelha tenta sistematizar os dados.

\section{REGRESSÃo EXPLICATIVA E MODELO DE PREVISÃO PARA A VARIÁVEL VOTO;}

Construiu-se uma regressão "Quasi Poison” para explicar a variável voto a partir das variáveis "despesa", "sexo", "sigla" e "reeleição". Na figura abaixo, o resultado mostra que as variáveis testadas são todas explicativas para a variável voto, ou seja elas são determinantes para o voto, isso é comprovado quando verificamos o p valor, abaixo de 0,05 em todas:

\section{FIGURA 6. REGRESSÃO QUASI POISSON - VOTO POR DESPESA, SEXO, SIGLA E}

\section{REELEIÇÃO.}

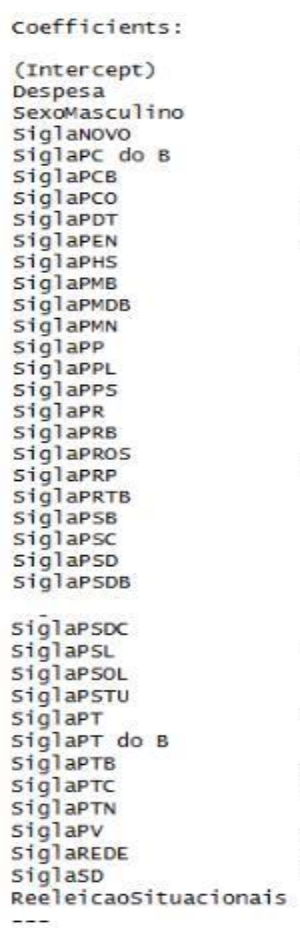

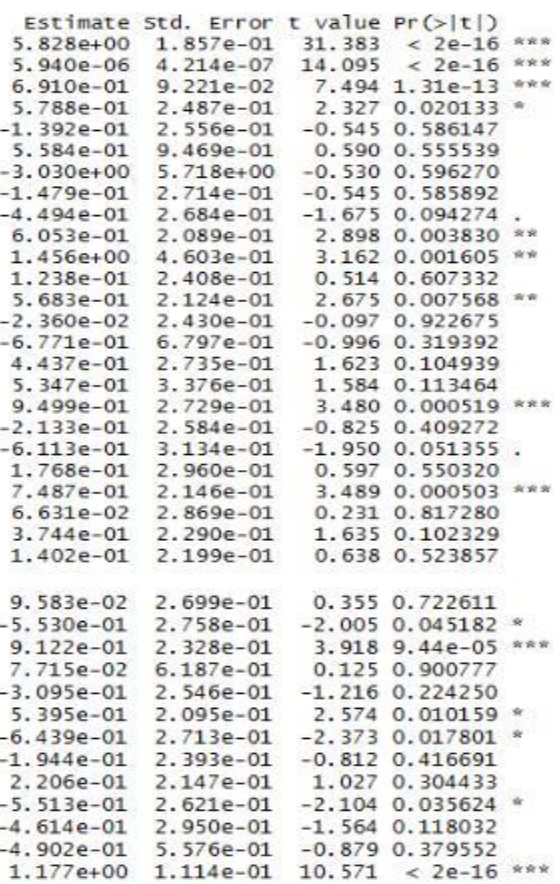

Fonte: O autor, a partir dados do TSE (2018).

Para complementar a explicação da regressão, esse gráfico mostra o comportamento dos dados e a reta de regressão. Nota-se que a reta traçada explica a maior parte dos dados. A reta pontilhada representa a regressão. 


\section{FIGURA 7. REGRESSÃO QUASI POISSON - VOTO POR DESPESA, SEXO, SIGLA E REELEIÇÃO.}

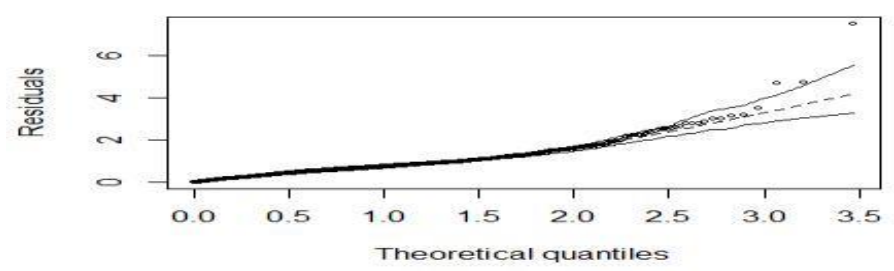

Fonte: O autor, a partir dados do TSE (2018).

A partir daí, foi criado um modelo que com o dado dessas variáveis previu um banco de dados de mesmo tamanho do utilizado. Comparou-se a capacidade preditiva do modelo para a variável total de votos, a partir dessas categorias. Para ajustes de valores, foi utilizada a expressão logarítmica das variáveis numéricas. O log conserta distorções de valores, como é o caso dos dados observados. A variação é enorme: tem candidato que gastou $\mathrm{R} \$ 64,00$ e até o que gastou mais, $\mathrm{R} \$ 448.127,00$.

\section{FIGURA 12. MODELO VS. DADOS}

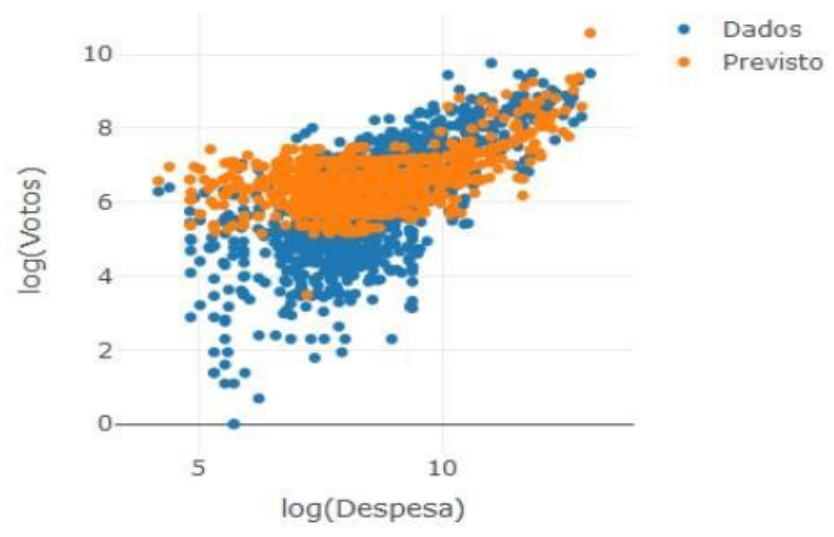

Fonte: O autor, a partir dados do TSE (2018).

Observa-se que os dados previstos tendem a acompanhar os reais. Pode-se citar que alguns dados da previsão não conseguem explicar alguns dos dados ocorridos. Isso pode ocorrer por diversas causas. A principal, o voto é uma confluência de diversos aspectos cognitivos e sociais que não são sistematizados por apenas uma variável. Para mais, outras variáveis não presentes no modelo poderiam explicar uma parte de votos como, por exemplo, o apoio institucional partidário, a 
idade dos candidatos, etc. Entretanto ainda que se tenha essas observações, o modelo de predição produzido tem uma boa capacidade explicativa, o que significa que apenas essas características, para o caso estudado, conseguem explicar boa parte dos votos.

\section{CONSIDERAÇÕES FINAIS}

Destaca-se que o efeito do dinheiro investido nas campanhas, ainda foi bem importante, a correlação estatística, 0,69, entre ambas as variáveis é considerada de moderada a forte. A máxima se manteve: dinheiro ainda foi responsável por gerar votos, mesmo com todas as mudanças que baratearam as campanhas. Os dados mostram, entretanto um detalhe instigante, dinheiro faz ser eleito mas não faz ser o mais votado. Isso é visto com a regressão entre as duas variáveis, apenas para os eleitos. Não existe correlação entre os eleitos, o p-valor é maior que 0,05.

No ano de 2016, os candidatos eleitos para a campanha de vereança em Belo Horizonte, gastaram em média, $\mathrm{R} \$ 16,50$ por voto recebido, quase a metade se espelhado com a eleição de 2012, cujo custo médio foi de $\mathrm{R} \$ 27,00$. Esse custo caiu bastante, mas dinheiro ainda explica muita coisa: para o pleito estudado, os eleitos gastaram 9 vezes mais do que os não eleitos. E a regressão entre dinheiro e voto mostra um p valor extremamente baixo o que faz aceitar a hipótese alternativa, isto é dinheiro está associado com o total de votos.

Com a regressão, percebeu-se que a variável "sexo", "sigla, "reeleição" e "despesa" são bem explicativas para o total de votos. Todas essas variáveis estiveram relacionadas com a chance de vitória de um candidato. Significa dizer que, o voto foi causado por: a)quanto cada campanha investiu; b)pelo fato do candidato ser homem ou mulher; c)pela agremiação partidária pela qual disputou a corrida eleitoral e d)pelo fato de ser situacional ou desafiante. O primeiro ponto, diz sobre a quantidade de despesa, e conforme dito na revisão bibliográfica, constantemente, a quantia investida pelas campanhas está associada a quantidade de votos. O sexo é importante para explicar o voto, em um país onde as mulheres têm menor representação legislativa que os homens, e elas são mais da metade da população, pode-se sugerir que candidaturas masculinas tendem a ter maior aceitação do eleitorado, as explicações podem ir desde a quantidade de homens nos ambientes políticos até a uma questão histórica de machismo presente na política brasileira.

A sigla partidária explica o resultado final, isso transmite que o eleitorado da capital mineira pode votar também considerando aspectos ideológicos e/ou de afinidade partidária. Em uma eleição tão personalista como a brasileira, partidos específicos ainda são puxadores de voto, atrelado a isso, 
existe a regra do coeficiente partidário que faz com que a eleição seja mais concorrida em alguns partidos e em outros não.

O último fator, a reeleição (incumbency) induz a pensar que mesmo em uma eleição com uma taxa de renovação muito superior à da eleição para o Senado estadunidense, os candidatos situacionais continuam partindo de um patamar mais elevado que os desafiantes, o que reforça o efeito "Jacobson", dinheiro é mais decisivo para os desafiantes. (JACOBSON, 1978) Mas vale o comentário que, entre os 5 eleitos que mais gastaram, 4 eram situacionais, o que sugere que ser situacional pode estar atrelado a ter mais dinheiro. Entretanto, se Jacobson (1978) previu que a melhor solução para a disputa ser mais justa era o Fundo Público de Campanha, o limite de gastos proposto por Samuels (2001) não minimizou a importância do dinheiro nas campanhas, mas as barateou significativamente.

A construção e transparência dos dados produzida diz muito também sobre alguns pontos do sistema brasileiro. Foram observadas 25 campanhas que não obtiveram votos, porém todas investiram quantias acima de $\mathrm{R} \$ 200,00$, e 5 investiram mais de $\mathrm{R} \$$ 5.000,00. Essa condição propicia um questionamento acerca dos candidatos "laranja" e até de práticas de "caixa-dois" em campanhas paralelas para um candidato majoritário.

As campanhas de 2016 foram significativamente mais baratas. Apesar disso, as circunstâncias apresentadas permitem concluir que em para o caso estudado, dinheiro foi decisivo e causador de votos. Sexo, partido e incumbency também são variáveis explicativas para o total de votos. De maneira geral, o modelo construído com esses 4 controles conseguiu prever boa parte dos casos.

Sublinha-se que o voto pode estar submetido a fatores não controláveis pelos aspectos matemáticos como por exemplo, o contexto específico de uma eleição. Mas o contexto pode ser fator também que explica os números, o partido do prefeito eleito elegeu 4 vereadores e junto ao PTN é o partido que possui mais vereadores.

Por fim, as conclusões geradas permitem que se compare cenários eleitorais em diferentes localidades, será que dinheiro importa da mesma forma em todo lugar do Brasil? A replicabilidade desse estudo para outros pleitos e cargos é uma possibilidade de aprofundamento da discussão feita. Outras questões surgem em perspectiva, o que fazem os candidatos que quebram o papel decisivo do dinheiro: as campanhas mais baratas que vencem constroem saídas em uma competição acirrada na qual dinheiro ainda importa muito, a eleição. 
De todo modo, pode ser afirmado com força empírica que na campanha ao cargo de vereador, em 2016, dinheiro ainda gerou voto e teve papel decisivo.

\section{REFERÊNCIAS BIBLIOGRÁFICAS}

ANSOLAHERE, S.; FIGUEIREDO, J.; SNYDER, J. Why is there so little money in U.S. politics? Journal of Economic Perspectives. Volume 17, No. 1, pp 105-130 Junho, 2003.

ARRAES, R.; NETO, O. ; SIMONASSI, A. .Despesas de Campanha eSucesso Eleitoral nos Pleitos Legislativos Brasileiros. Revista de Ciências Sociais, Rio de Janeiro, vol.60, nº 4 , pp. 1059-1093, 2017.

BACKES, A.L. e SANTOS, L. Gastos em Campanhas Eleitorais no Brasil. Caderno ASLEGIS. No. 46, pp. 47-59, Maio-Agosto, 2012.

CLEVELAND WILLIAM. Robust locally weighted regression and smoothing scatterplots. Journal of the American Statistical Association, v.74, p. 829-836, 1979.

CERVI, E. Financiamento de campanhas e desempenho eleitoral no Brasil: análise das contribuições de pessoas físicas, jurídicas e partidos políticos às eleições de 2008 nas capitais de Estado". Revista Brasileira de Ciência Política, No. 4., pp. 135-167, Julho-Dezembro, 2010.

CASTRO, M; NUNES, F. Candidatos corruptos são punidos?: accountability na eleição brasileira de 2006. Opin. Publica, Campinas , v. 20, n. 1, p. 26-48, Abril 2014.

COWDEN,J.,GREEN,D.;KRASNOJ.;eTheDynamicsofCampaignFundraisinginHouse Elections. The Journal of Politics, vol 56, No. 2, pp 459-474, Maio, 1994.

DOWNS, A. An Economic Theory of Democracy. 1a edição. Ed. Harper. New York. 1957.

FIGUEIREDO FILHO, D. B., Gastos eleitorais: os determinantes das eleições? Estimando a influência dos gastos de campanha nas eleições de 2002. Revista Urutágua. Maringá, Brasil. Quadrimestral, No. 08, Dez/Jan/Fev/Mar , 2005.

48

GERBER, A. Estimating the Effect of Campaign Spending on Senate Election Outcomes Using Instrumental Variables. The American Political Science Review, Vol. 92, No. 2, pp. 401-411, Junho de 1998.

GIORA, G.; REBELLO, M.; SCAPINI, M. Dinheiro realmente importa? Uma análise do financiamento de campanha nas eleições para a ALERGS em 2014. REVISTA DEBATES, Porto Alegre, v. 10, n. 3, p. 169-188, set-dez. 2016.

JACOBSON, G. The Effect of Campaign Spending in Cogressional Ellections.The American Political Science Review, Vol. 72, No. 2, pp. 469-491, Junho, 1978.

JACOBSON, G.; KERNELL, S. Strategy and Choice in Congressional Elections. 2a edição.

Ed. Yale University Press. New Haven. 1981. 
JACOBSON, G. The Effect of Campaign Spending in House Elections: New Evidence for Old arguments. American Journal of Political Science, Vol. 34, No. 2, pp. 334-362, Maio, 1990.

LEMOS, L.; MARCELINO, D.; PEDERIVA, J. H. Porque dinheiro importa: a dinâmica das contribuições eleitorais para o Congresso Nacional em 2002 e 2006. Opinião Pública, Campinas , vol. 16, No. 2, p. 366-393, Novembro, 2010 .

MANCUSO, W. Investimento eleitoral no Brasil:balanço da literatura(2001-2012)e Agenda de Pesquisa. Revista de Sociologia e Política, vol,23, nº54, pp.155-183, Junho, 2015.

NICOLAU, J. O sistema eleitoral de lista aberta no Brasil.Dados, Rio de Janeiro, v.49,n.4, p. 689-720, 2006.

PALDA, F.; PALDA,K.The impact of campaign expenditures on political competition in the French legislative elections of 1993. Public Choice. pp: 94-157. Janeiro, 1998. PEIXOTO, V. Impacto dos gastos de campanhas nas eleições de 2006-32 $2^{\circ}$ EncontroAnual da ANPOCS, 2008.

R Core Team (2017). R:A language and environment for statistical computing.R Foundation for Statistical Computing, Vienna, Austria. URL https://www.R-project.org/. 49

SAMUELS, D. Incumbents and Challengers on a Level Playing Field: Assessing the Impact of Campaign Finance in Brazil. The Journal Of Politics, Vol 63, No. 2, pp. 569-584, Maio, 2001a.

SAMUELS, D. Does Money Matter? Credible Commitments and Campaign Finance in New Democracies: Theory and Evidence from Brazil. Comparative Politics, vol 34, No. 2, pp. 23-42, Outubro, 2001b.

SAMUELS, D. Pork Barreling is not Credit Claiming or Advertising:Campaign Finance and the Source of the Personal Vote in Brazil.The Journal of Politics,vol 64,No.3,pp.845-863., Dezembro, 2002.

SAMUELS, David J. (2006). "Financiamento de Campanha no Brasil e Proposta de Reforma”, in G.A.D.Soares e L. Rennó(orgs.), Reforma Política: Lições da História Recente. Rio de Janeiro, FGV Editora, pp 133-153.

SPECK, B; MANCUSO, W. O que faz a diferença? Gastos de campanha, capital político, sexo e contexto municipal nas eleições para prefeito de 2012. Cadernos Adenauer Vol. 14, No. 2, p. 109-126, 2013.

STONE C. J. Consistent nonparametric regression, with discussion. The annals of Statistics, vol. 5 pp. 549-645, 1977.

STONE C. J. Optimal rates of convergence for nonparametric estimators. The annals of Statistics, vol.8 pp..1348-1360, 1980. 
TRIBUNAL SUPERIOR ELEITORAL. Repositório de dados estatísticos: 2016. http://www.tse.jus.br/eleicoes/estatisticas/repositorio-de-dados-eleitorais-1/repositorio-de-dad oseleitorais - Acesso em 20/3/2018.

TRIBUNAL SUPERIOR ELEITORAL. Repositório de dados estatísticos: 2016. http://divulgacandcontas.tse.jus.br/divulga/\#/ - Acesso em 23/3/2018.

TRIBUNAL SUPERIOR ELEITORAL. Gastos de Campanha: 2016. http://www.justicaeleitoral.jus.br/arquivos/gastos-de-campanha-2012-e-2016 - Acesso em 25/3/2018. 